\title{
Prevalence and Risk Factors of Intestinal Parasites in Cats from China
}

\author{
Yurong Yang and Hongde Liang \\ Laboratory of Veterinary Pathology, College of Animal Science and Veterinary Medicine, Henan Agriculture University, \\ Zhengzhou 450002, China
}

Correspondence should be addressed to Hongde Liang; hdliang12@163.com

Received 16 January 2015; Revised 28 April 2015; Accepted 29 April 2015

Academic Editor: Terry K. Smith

Copyright (c) 2015 Y. Yang and H. Liang. This is an open access article distributed under the Creative Commons Attribution License, which permits unrestricted use, distribution, and reproduction in any medium, provided the original work is properly cited.

\begin{abstract}
The prevalence of intestinal parasites in cats from China was largely unknown prior to this study. The aim of the present study was to investigate the presence of intestinal parasites in cats from central China and also identify risk factors for parasitism. Fecal samples from 360 cats were examined using sugar flotation procedure and fecal smear test by microscope. Cats had mixed two or three kinds of parasites infections. Of the 360 cats feces, intestinal parasites positive feces were 149 (41.39\%). 64 (17.78\%) were infected with Toxocara cati, 61 (16.94\%) with Isospora felis, 41 (11.39\%) with Isospora rivolta, 33 (9.17\%) with Paragonimus, 23 (6.39\%) with hookworms, 11 (3.06\%) with Toxoplasma-like oocysts, 10 (2.78\%) with Trichuris, 4 (1.11\%) with lungworm, 2 (0.56\%) with Sarcocystis, and $1(0.28 \%)$ with Trematode. The cats' living outdoor was identified as risk factor by statistical analysis. These results provide relevant basic data for assessing the infection of intestinal parasites in cats from central region of China. In conclusion, there was high prevalence of intestinal parasites in cats from China.
\end{abstract}

\section{Introduction}

Gastrointestinal parasitism is one of the main causes of morbidity in domestic cats. The prevalence of intestinal parasites was varied due to geographical region, presence and frequency of veterinary care, season of the year, and the type of population of cat (stray, feral, shelter, household). The number of domestic cats in China (53 million) is quarter of the world (http://www.mapsofworld.com/world-top-ten/countries-with-most-pet-cat-population.html). But, little information on the prevalence of intestinal parasites in cats is available.

Here, we report the prevalence of intestinal parasites in cats from central China. This information is essential to veterinarians for the development of strategies for treatment and control of parasites and for public health authorities concerned with monitoring the zoonotic potential of infections in cats. The purpose of this study was to determine the regional prevalence of intestinal parasites and also identify risk factors for parasitism.

\section{Materials and Methods}

2.1. Cat Feces Study Area and Sampling. The survey was carried out in the central of China. The cat feces were collected from two major parts: Henan and Beijing. Henan (Latitude $34.90^{\circ} \mathrm{N}$, Longitude $113.50^{\circ} \mathrm{E}$ ) has a humid warmtemperate climate. The climate in Beijing (Latitude $39.54^{\circ} \mathrm{N}$, Longitude $116.23^{\circ} \mathrm{E}$ ) belongs to the warm temperate zone, half moist continental monsoon climate. The samples from Beijing ( 61 feces) came from one cat shelter. The samples from Henan came from stray cats ( 32 feces), market cats ( 205 feces), and household cats (62 feces). Total 360 cats fecal samples were collected by Veterinary pathology laboratory, Henan Agriculture University from 2013 2014.

2.2. Fecal Examination by Microscopy. Samples were examined by a conventional flotation method using $530 \mathrm{~g} / \mathrm{L}$ sugar (specific gravity 1.15) as previously described [1]. Floating material was transferred to a slide and examined by light microscopy. The parasite eggs were differentiated according to their morphologic characteristics.

2.3. Statistical Analysis. The prevalence and frequency distribution of overall infection and of each parasite were tested by Graphpad software using Chi-square test. The analysis was performed considering the following independent variables: age ( $\leq 12$ months old, $>12$ months old), management 
TABLE 1: Prevalence and confidence interval of intestinal parasites in 360 cat feces from China.

\begin{tabular}{|c|c|c|c|}
\hline Parasites & $\begin{array}{c}\text { Beijing } \\
\text { Number of positive results } \\
\text { Prevalence } \% \\
(95 \% \mathrm{CI}) \\
\end{array}$ & $\begin{array}{c}\text { Henan } \\
\text { Number of positive results } \\
\text { Prevalence } \% \\
(95 \% \mathrm{CI}) \\
\end{array}$ & $\begin{array}{c}\text { Total } \\
\text { Number of positive results } \\
\text { Prevalence } \% \\
(95 \% \mathrm{CI})\end{array}$ \\
\hline \multirow{3}{*}{ Toxocara cati } & 1 & 63 & 64 \\
\hline & 1.64 & 21.07 & 17.78 \\
\hline & $(0.01-9.55)$ & $(16.82-26.06)$ & $(14.16-22.08)$ \\
\hline \multirow{3}{*}{ Isospora felis } & 3 & 58 & 61 \\
\hline & 4.92 & 19.40 & 16.94 \\
\hline & $(1.14-14.03)$ & $(15.30-24.27)$ & (13.41-21.18) \\
\hline \multirow{3}{*}{ Isospora rivolta } & 1 & 40 & 41 \\
\hline & 1.64 & 13.38 & 11.39 \\
\hline & $(0.01-9.55)$ & $(9.95-17.73)$ & $(8.48-15.11)$ \\
\hline \multirow{3}{*}{ Hookworms } & 1 & 22 & 23 \\
\hline & 1.64 & 7.36 & 6.39 \\
\hline & $(0.01-9.55)$ & $(4.86-10.94)$ & $(4.25-9.44)$ \\
\hline \multirow{3}{*}{ Paragonimus } & 0 & 33 & 33 \\
\hline & - & 11.04 & 9.17 \\
\hline & - & $(7.93-15.13)$ & $(6.57-12.62)$ \\
\hline \multirow{3}{*}{ Trematode } & 1 & 0 & 1 \\
\hline & 1.64 & - & 0.28 \\
\hline & $(0.01-9.55)$ & - & $(<0.01-1.72)$ \\
\hline \multirow{3}{*}{ Trichuris } & 0 & 10 & 10 \\
\hline & - & 3.34 & 2.78 \\
\hline & - & $(1.75-6.13)$ & $(1.45-5.11)$ \\
\hline \multirow{3}{*}{ Toxoplasma-like } & 0 & 11 & 11 \\
\hline & - & 3.68 & 3.06 \\
\hline & - & $(1.99-6.54)$ & $(1.65-5.45)$ \\
\hline \multirow{3}{*}{ Lungworm } & 0 & 4 & 4 \\
\hline & - & 1.34 & 1.11 \\
\hline & - & $(0.40-3.51)$ & $(0.33-2.93)$ \\
\hline \multirow{3}{*}{ Sarcocystis } & 0 & 2 & 2 \\
\hline & - & 0.67 & 0.56 \\
\hline & - & $(0.02-2.57)$ & $(0.02-2.14)$ \\
\hline \multirow{3}{*}{ Overall prevalence } & $4 / 61$ & $145 / 299$ & 149 \\
\hline & 6.56 & 48.49 & 41.39 \\
\hline & $(2.12-16.14)$ & $(42.89-54.14)$ & $(6.42-46.54)$ \\
\hline
\end{tabular}

(outdoor or household), and habitation (Beijing or Henan). In statistical tests, $P<0.05$ was regarded as significant.

2.4. Ethics. All investigations reported here were approved by the institutional animal use protocol committee of the Henan Agriculture University, China.

\section{Results}

The overall prevalence of intestinal parasites was $41.39 \%$ in cats (Table 1). The cats frequently mix infected two parasite species or three parasite species. Toxocara cati was the most prevalent species detected (17.78\%) and then were Isospora felis (16.94\%), Isospora rivolta (11.39\%), Paragonimus $(9.17 \%)$, hookworms (6.39\%), Toxoplasma-like oocysts (3.06\%),
Trichuris (2.78\%), lungworm (1.11\%), Sarcocystis (0.56\%), and Trematode $(0.28 \%)$. The predominant predictors of intestinal parasite infection were habitation and housing. The infection rate of older cats and younger cats had no significant difference $(\mathrm{OR}=1.01)$. Housing had impressive effect on the infection; outdoor cats showed higher infection risk than household cats $(\mathrm{OR}=2.66)$. Cats from Beijing area showed less exposure to infections than cats from Henan area $(\mathrm{OR}=13.42)$ (Table 2$)$.

All fecal floats were bioassayed in mice for another project (isolation T. gondii) irrespective of microscopic examination results. For mice bioassay, fecal floats were inoculated into SW and IFN- $\gamma$ knockout mice in pools. 1 viable $T$. gondii was found from the cat feces. Isospora felis cysts were found in smear of the mesenteric lymph nodes of IFN- $\gamma$ knockout 


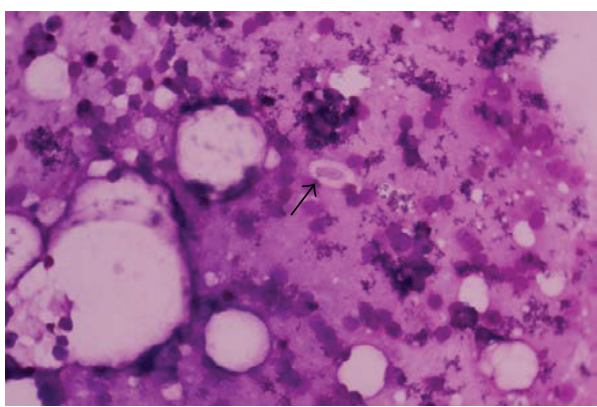

(a)

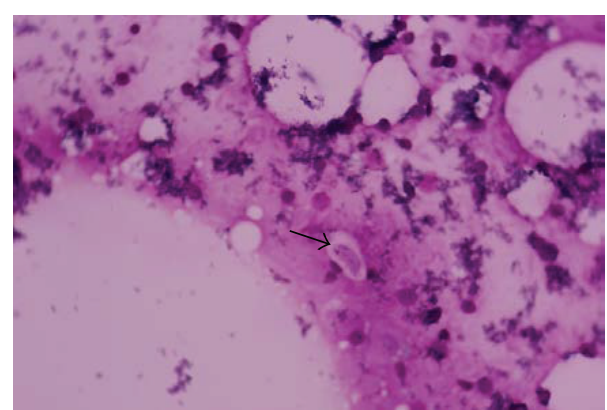

(b)

Figure 1: Results from smear revealed Isospora felis infection from the cat feces. Giemsa's stain $\times 1000$. Two figures are photomicrographs of the cyst of Isospora felis (arrow). The IFN- $\gamma$ knockout mice were inoculated cat fecal floats orally. The mice were killed at 6 weeks postinfection. The smears were from mesenteric lymph nodes of IFN- $\gamma$ knockout mice.

TABLE 2: Final multivariate analysis of risks factors associated with intestinal parasites in cats in China.

\begin{tabular}{lcccc}
\hline Variable & Risk factor & OR & $95 \%$ CI & $P$ value \\
\hline \multirow{2}{*}{ Age } & $\leq 12$ months & 1.00 & & NA \\
& $>12$ months & 1.01 & $0.55-1.84$ & 0.97 \\
\hline \multirow{2}{*}{ Housing } & Household & 1.00 & & NA \\
& Outdoor & 2.66 & $1.71-4.15$ & $<0.0001$ \\
\hline \multirow{2}{*}{ Habitation } & Beijing & 1.00 & & NA \\
& Henan & 13.42 & $4.75-37.92$ & $<0.0001$ \\
\hline
\end{tabular}

OR: odds ratio; (CI) 95\%: confidence interval.

mice 6 weeks postinfection (Figure 1 ). The size of sheath or cyst-like structures was $12.3 \times 4.2 \mu \mathrm{m}$, not including sheath, and $19.4 \times 12.2 \mu \mathrm{m}$ with the sheath in smear. The Isospora felis cysts positive samples are all from Henan. But, we do not further check which sample and how many samples were positive for Isospora felis. From the muscle of IFN- $\gamma$ knockout mice, the cysts of Hammondia hammondi were not found.

\section{Discussion}

This survey found the most common protozoa and helminth infections in cats were Toxocara cati, Isospora felis, Isospora rivolta, Paragonimus, hookworm, and Trichuris (Table 1). This represents the first comprehensive intestine parasites survey of cats from China. The investigation of the prevalence of gastrointestinal parasites in cats had been done in several countries. It was $8.6 \% \sim 35 \%$ in the world [2-8]. In our study, the overall prevalence of intestinal parasites in cats was $41.39 \%$; the prevalence of intestine parasites in cats from China was higher than other places' cat population. The different locations or housing had more difference: $48.49 \%$ in Henan province and $6.56 \%$ in Beijing; $28.48 \%$ in household cats and $51.49 \%$ in outdoor cats.

Toxocariasis is a widespread zoonosis caused by the Toxocara canis and Toxocara cati, which primarily infect dogs and cats, respectively. Toxocara cati could infect human and induce disease. Compared with another study in China, the epidemiological study of toxocariasis showed a seroprevalence of $12.25 \%(351 / 2866)$ in human [9]. Compared with a number of other studies (3.2\% 22.2\%) [3-5], Toxocara cati were found at a higher infection rate $(17.78 \%)$ in our survey. Hookworm parasites were common helminth in cat; the prevalence in this study is $6.39 \%$. This is lower than previous reports in other parts of China, and the infection rate of hookworms in cats from Sichuan and Guangdong was $25 \% \sim 95 \%$ by necropsy or PCR [10]. Hookworms may cause zoonotic disease. Feline hookworm Ancylostoma ceylanicum larval infection in human could lead to hookworm associated cutaneous larva migrans. $2.78 \%$ (10/360) Trichuris eggs were found in this study. Human Trichuris Trichiura, pig Trichuris suis, and dog Trichuris vulpis could cause diarrhea and inflammation of the cecum and colon [11]. There are two species of whipworms (Trichuris serrata, Trichuris campanula) that can infect cats. But, to date there are no studies documenting clinical signs or pathology of them. The zoonotic potential of Trichuris in cats should be assessed further. $1.11 \%(4 / 360)$ cats were infected with lungworms. Lungworms could cause respiratory problems in cats. The most common types of worm to affect cats are Aelurostrongylus abstrusus and Capillaria aerophila. Prevalence rates of lungworms in cats from China are rare. Global prevalence rates vary from 50\% in cats from Albania to $1 \%$ in cats from Spain [12].

Paragonimus has been reported infecting animals and humans, which have been identified in many parts of the world, including China [13]. The cats acting as a reservoir host of Paragonimus. Seroprevalence of Paragonimus in human from China ranges from $1.9 \%$ to $33.7 \%$ [14]. In cats, it was from $0.6 \% \sim 44.7 \%$ in China $[15,16]$. Compared to the prevalence of Paragonimus in 1980s in China, the prevalence of Paragonimus infection decreased in 2000s because of the disappearance of some wild animals and the shutdown of the life cycle. In this survey, the prevalence of Paragonimus in cat feces was $9.17 \%$, all positive in Henan province.

We found a higher proportion of samples positive for $I$. felis (16.94\%) and Isospora rivolta (11.39\%) in this study from cat feces. I. felis and I. rivolta appear to be non pathogenic for cats [17]. The prevalence of Isospora in cats was 2.2\% 9.0\% in the world $[6,7,18]$. The survey about the prevalence of Isospora in China was rare and only in Chinese journal, it was 28.4\% 33.0\% in China [19, 20]. 3.06\% (11/360) Toxoplasmalike oocysts were found in this study. Toxoplasma-like oocysts 
include Toxoplasma gondii and $H$. hammondi. T. gondii and $H$. hammondi were closely related tissue cyst forming coccidian parasites with a two-host life cycle. T. gondii causes infectious diseases in humans and animals [1], whereas no disease has yet been associated with $H$. hammondi [21]. Unlike T. gondii, which can be continuously passaged in mice, only the oocysts of $H$. hammondi are infective to mice and it cannot be maintained beyond the first mouse passage. The oocysts of both species (T. gondii and H. hammondi) were regarded as undistinguishable morphologically and serologically. The identification of the oocysts was accomplished by using molecular techniques or biological analysis in IFN$\gamma$ knockout mouse [22]. In natural environment, T. gondii oocysts were found in $1 \%$ of cats at any given time according to fecal surveys from 1988 2008 [1].

Our study is subject to limitations. First, only one fecal sample from each cat was collected and examined in the present study. Prepatent infections and the intermittent shedding of parasite stages may lead to underestimation of the prevalence of parasitic infection. Second, the cats feces from Beijing sample were all from one animal shelter. The results might not represent all the cat population in Beijing. It is better to collect sample consecutively from the same cat and collect different kinds of cats feces in the future survey.

\section{Conclusion}

The prevalence of intestinal parasites in cat from China was higher than in most cat population worldwide, especially Toxocara cati, Isospora felis, Isospora rivolta, and Paragonimus. The cat fecal information may represent a potential zoonotic risk of Toxocara cati, hookworm, and Paragonimus for human. Treatment and care should control these intestinal parasites in China. Risk groups like children and immunocompromised individuals should take special care during contact with cats. This study provided relevant basic data for veterinaries to develop strategies for treatment and control of parasites and for public health authorities concerned with monitoring the zoonotic potential of infections in cats.

\section{Conflict of Interests}

The authors declare that there is no conflict of interests regarding the publication of this paper.

\section{Acknowledgments}

This research project was financed by the Natural Science Foundation of China (30800812). The authors would like to acknowledge QiongFang Zhang, JingJing Kang, YangGuang Kong, WenJie Zhao, XiaoYing Fu, LiKui Huang, and YongJie Feng for collecting samples. The authors also would like to acknowledge JP Dubey for kind suggestions.

\section{References}

[1] J. P. Dubey, Toxoplasmosis of Animals and Humans, CRC Press, Taylor \& Francis, Boca Raton, Fla, USA, 2nd edition, 2010.
[2] T. R. McGlade, I. D. Robertson, A. D. Elliot, C. Read, and R. C. A. Thompson, "Gastrointestinal parasites of domestic cats in Perth, Western Australia," Veterinary Parasitology, vol. 117, no. 4, pp. 251-262, 2003.

[3] C. S. Palmer, R. C. A. Thompson, R. J. Traub, R. Rees, and I. D. Robertson, "National study of the gastrointestinal parasites of dogs and cats in Australia," Veterinary Parasitology, vol. 151, no. 2-4, pp. 181-190, 2008.

[4] F. Riggio, R. Mannella, G. Ariti, and S. Perrucci, "Intestinal and lung parasites in owned dogs and cats from central Italy," Veterinary Parasitology, vol. 193, no. 1-3, pp. 78-84, 2013.

[5] G. Miró, A. Montoya, S. Jiménez, C. Frisuelos, M. Mateo, and I. Fuentes, "Prevalence of antibodies to Toxoplasma gondii and intestinal parasites in stray, farm and household cats in Spain," Veterinary Parasitology, vol. 126, no. 3, pp. 249-255, 2004.

[6] V. Mircean, A. Titilincu, and C. Vasile, "Prevalence of endoparasites in household cat (Felis catus) populations from Transylvania (Romania) and association with risk factors," Veterinary Parasitology, vol. 171, no. 1-2, pp. 163-166, 2010.

[7] D. Barutzki and R. Schaper, "Results of parasitological examinations of faecal samples from cats and dogs in Germany between 2003 and 2010," Parasitology Research, vol. 109, supplement 1, pp. s45-s60, 2011.

[8] D. Barutzki and R. Sohaper, "Endoparasites in dogs and cats in Germany 1999-2002," Parasitology Research, vol. 90, supplement 3, pp. S148-S150, 2003.

[9] W. Cong, X. Zhang, N. Zhou et al., “Toxocara seroprevalence among clinically healthy individuals, pregnant women and psychiatric patients and associated risk factors in shandong province, eastern China," PLoS Neglected Tropical Diseases, vol. 8, no. 8, Article ID e3082, 2014.

[10] Y. Liu, G. Zheng, M. Alsarakibi et al., "Molecular identification of Ancylostoma caninum isolated from cats in southern china based on complete ITS sequence," BioMed Research International, vol. 2013, Article ID 868050, 6 pages, 2013.

[11] S. C. Ojha, C. Jaide, N. Jinawath, P. Rotjanapan, and P. Baral, "Geohelminths: public health significance," Journal of Infection in Developing Countries, vol. 8, no. 1, pp. 5-16, 2014.

[12] D. Barutzki and R. Schaper, "Occurrence and regional distribution of Aelurostrongylus abstrusus in cats in Germany," Parasitology Research, vol. 112, no. 2, pp. 855-861, 2013.

[13] J. Keiser and J. Utzinger, "Emerging foodborne trematodiasis," Emerging Infectious Diseases, vol. 11, no. 10, pp. 1507-1514, 2005.

[14] Q. Liu, F. Wei, W. Liu, S. Yang, and X. Zhang, "Paragonimiasis: an important food-borne zoonosis in China," Trends in Parasitology, vol. 24, no. 7, pp. 318-323, 2008.

[15] H. Q. Lou, Y. Hu, Y. J. Jin et al., "Investigation on the hosts with natural Paragonimus infection and species identification in Jinhua Prefecture of Zhejiang Province," Zhongguo Ji Sheng Chong Xue Yu Ji Sheng Chong Bing Za Zhi, vol. 29, pp. 348-352, 2011 (Chinese).

[16] M. S. Zhu, Y. X. Zhu, M. H. Song, and Z. J. Wang, "Epidemiologic survey of paragonimasia in reservoir region of SouthNorth water diversion project," Journal of Pathogen Biology, vol. 2, pp. 256-259, 2007 (Chinese).

[17] J. P. Dubey, "Intestinal protozoa infections," Veterinary Clinics of North America-Small Animal Practice, vol. 23, no. 1, pp. 37-55, 1993.

[18] J. H. Hoopes, L. Polley, B. Wagner, and E. J. Jenkins, "A retrospective investigation of feline gastrointestinal parasites in western Canada," The Canadian Veterinary Journal, vol. 54, no. 4, pp. 359-362, 2013. 
[19] Y. Meng and J. J. Hu, "The survey of Isospora in cat from kunming area," The Animal Husbandry and Veterinary, vol. 3, pp. 71-73, 2011 (Chinese).

[20] Z. Y. Ding, X. J. Zeng, X. Z. Yu, C. J. Huang, Y. J. Wang, and Y. F. Hu, "The survey of Toxoplasma gondii and Isospora rivolta in cat feces from Nanchang," Chinese Journal of Zoonoses, vol. 1, pp. 40-41, 1989 (Chinese).

[21] J. P. Dubey and C. Sreekumar, "Redescription of Hammondia hammondi and its differentiation from Toxoplasma gondii," International Journal for Parasitology, vol. 33, no. 13, pp. 1437-1453, 2003.

[22] J. P. Dubey and D. J. Ferguson, "Life cycle of Hammondia hammondi (apicomplexa: sarcocystidae) in cats," Journal of Eukaryotic Microbiology, vol. 62, no. 3, pp. 346-352, 2015. 

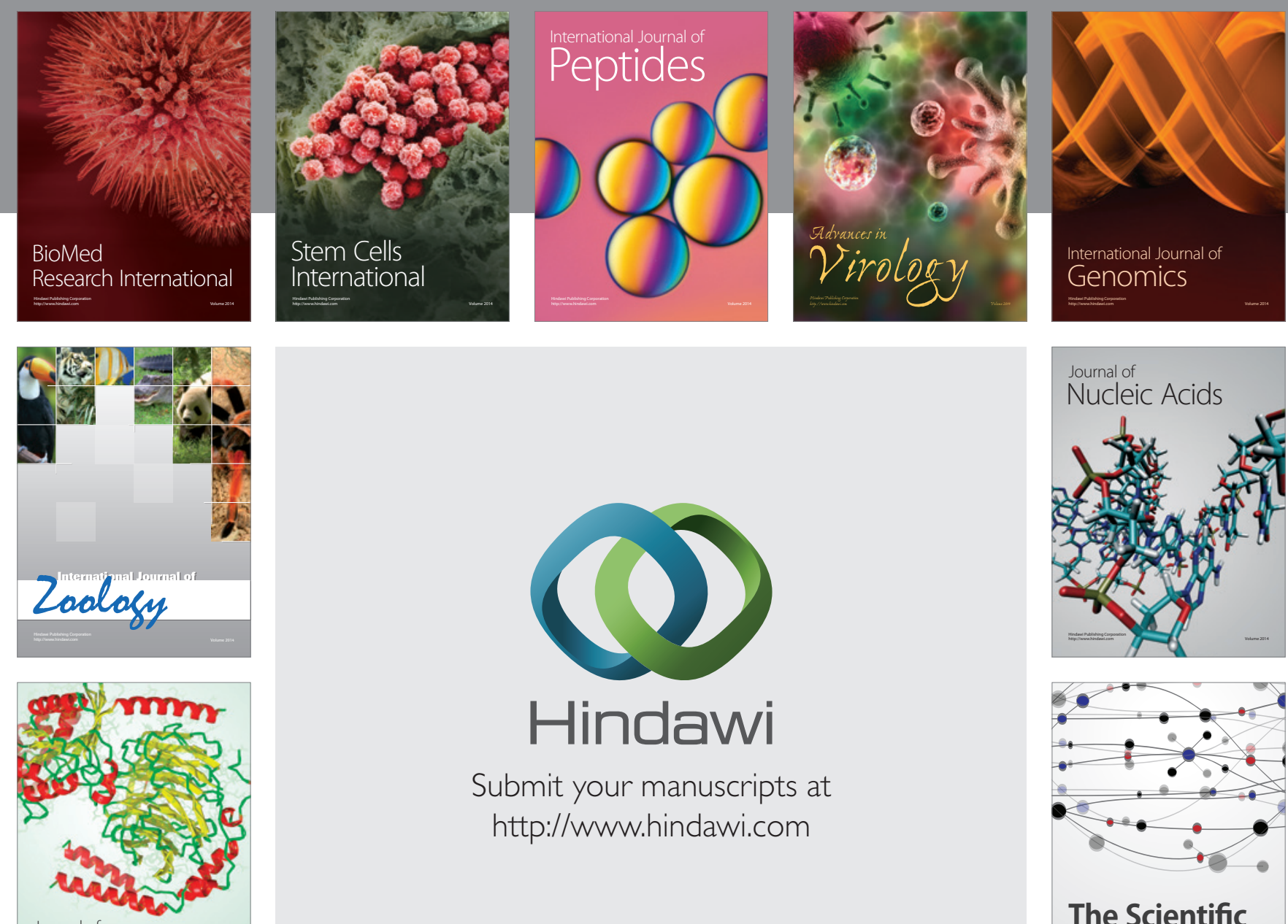

Submit your manuscripts at

http://www.hindawi.com

Journal of
Signal Transduction
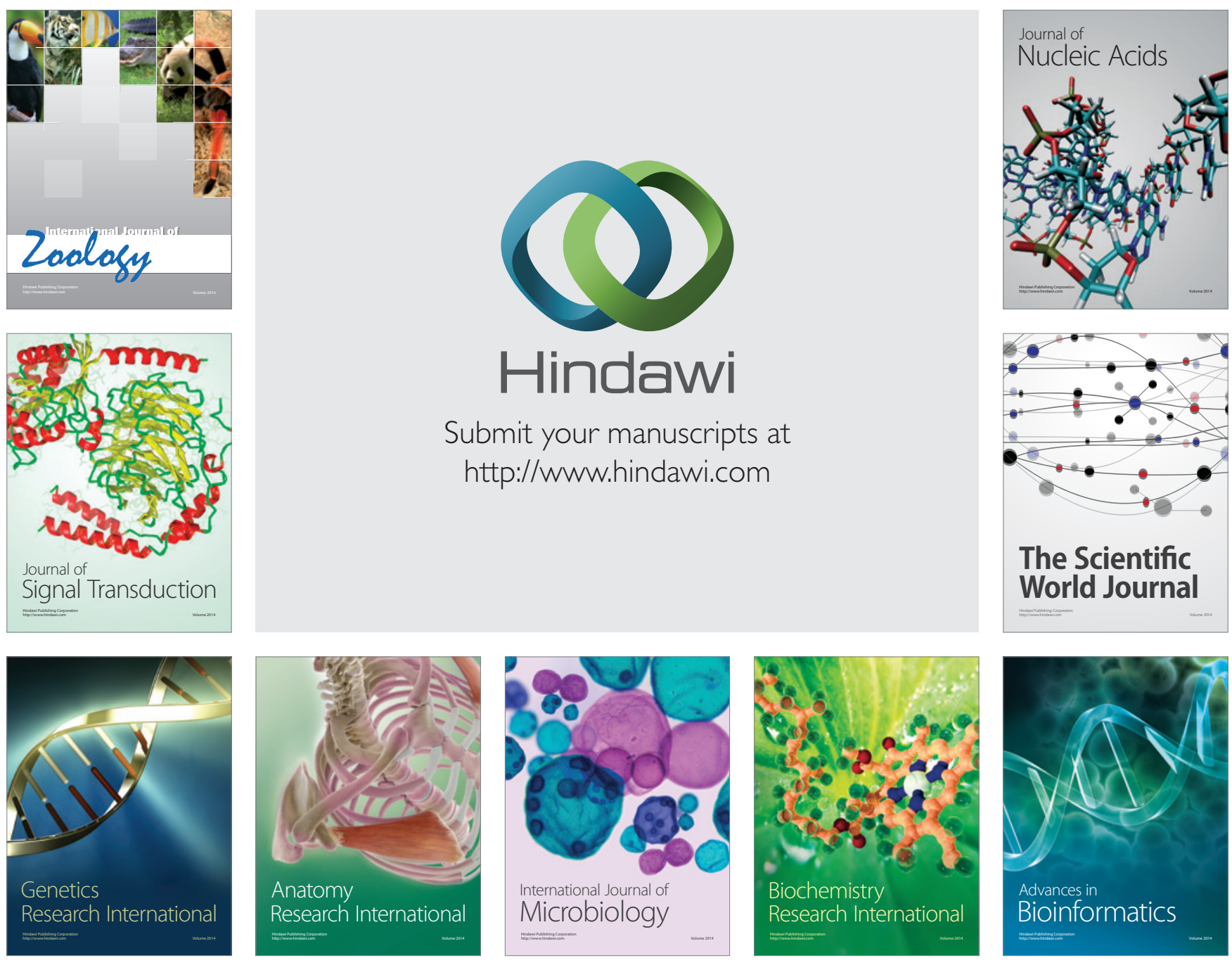

The Scientific World Journal
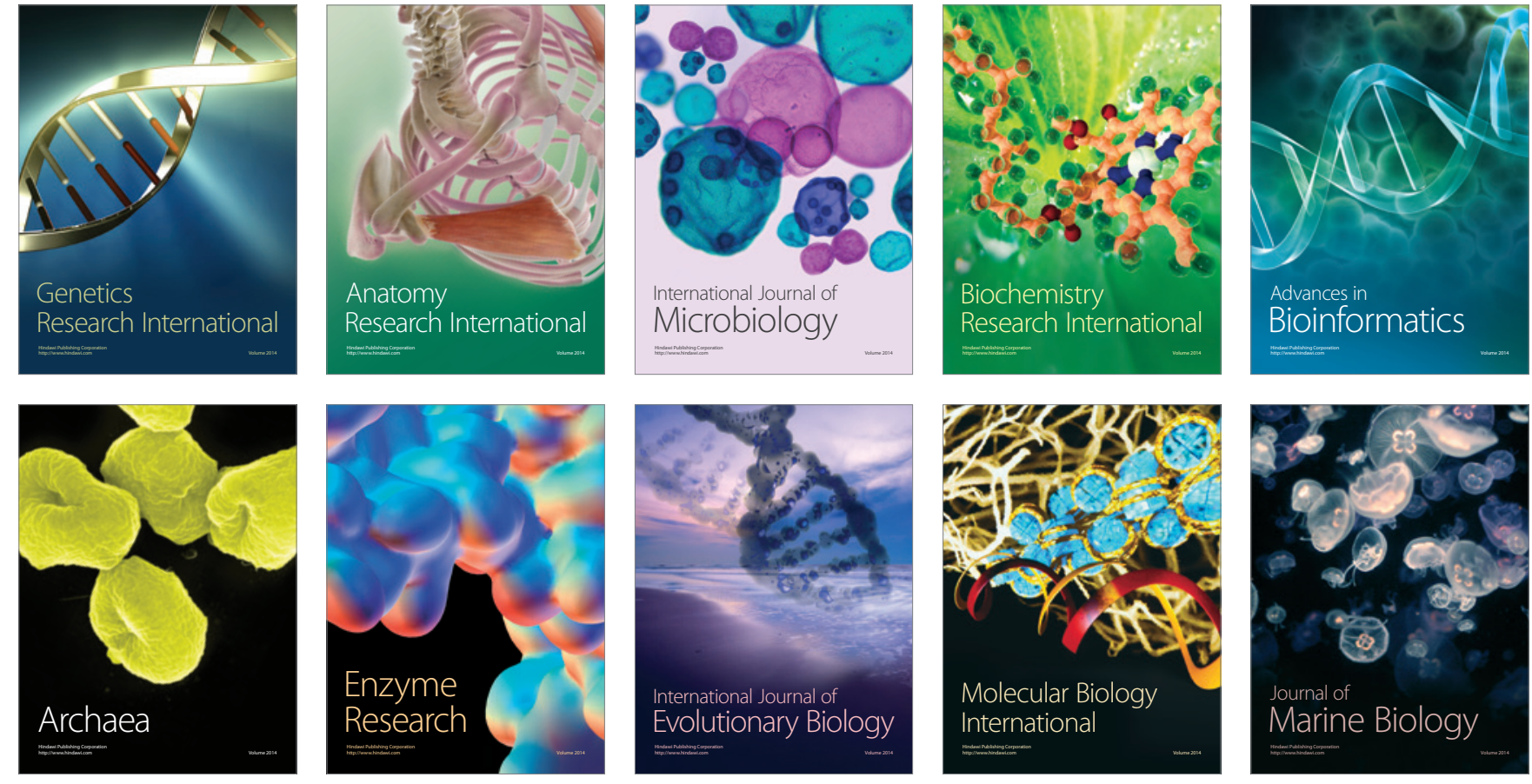